\title{
Public Policies, Institutions, and Economic Growth in Low-income and Lower Middle-income Countries: Further Empirical Evidence
}

\author{
Minh Quang Dao \\ Department of Economics, Eastern Illinois University, 600 E., USA
}

Copyright $\bigcirc 2017$ by authors, all rights reserved. Authors agree that this article remains permanently open access under the terms of the Creative Commons Attribution License 4.0 International License

\begin{abstract}
This paper examines the impact of public policies and institutions on economic growth in developing countries. The current study is superior to that by Dao [16] in that we specify a neoclassical growth model which incorporates public policies and institutions and subsequently formulate an empirical model to be estimated. This approach not only provides a more solid theoretical framework but also yields better empirical results that are not biased due to model misspecification. Based on data from the World Bank for the 2000-2015 period and a sample of thirty-nine low-income and lower middle-income economies we find that the growth rate of GDP is dependent on a country's economic management of its debt policy, its structural policies regarding the financial sector and the business regulatory environment, and its policies for social inclusion and equity dealing with gender equality, with building human resources, and with social protection and labor, along with the growth rates of inputs such as land, physical capital, general government consumption, and net exports. We observe that the coefficient estimates of two explanatory variables, namely, the structural policies regarding the financial sector and the policies for social inclusion and equity dealing with gender equality, do not have their expected sign, possibly to the collinearity between the structural policies regarding the financial sector and the debt policy variable, the business regulatory environment variable, the building human resources variable, and the social protection and labor variable and that between the gender equality variable and the business regulatory environment variable, the building human resources variable, and the social protection and labor variable. We also note that the business regulatory variable is not significant using the t-test, but its exclusion from the model results in a decrease in its explanatory power as measured by the adjusted coefficient of determination. We suspect that this is also due to the collinearity between this variable and three policies for social inclusion and equity variables. Statistical results of such empirical examination will assist
\end{abstract}

governments in developing countries focus on appropriate policies dealing with the economic management of debt policy, those of a structural nature regarding the financial sector and the business regulatory environment, and those for social inclusion and equity such as improving gender equality, building human resources and providing social protection and labor in order to foster economic growth. Public sector management and institutions, on the other hand, do not seem to influence a developing country's rate of economic growth.

Keywords Public Policies and Institutions, GDP Growth, Developing Countries

JEL Classifications: O12, O15, O40

\section{Introduction}

According to the 2013 World Development Report: Jobs [1], while the key engine of job creation is the private sector, being responsible for 90 percent of all jobs in the developing economies, governments also play a crucial role in ensuring that the conditions are present for robust private sector-led economic growth and in easing the constraints that prevent the private sector from creating good jobs for growth. The Report identifies the first stage in the approach to assist government meet these goals as policy fundamentals which include, among other things, macroeconomic stability and a business regulatory environment conducive to investment and hence to growth.

This paper attempts to estimate the impact of public policies and institutions on economic growth. The motivation for this study is twofold: First, it has been four years since the last empirical estimation of such impact was done. We are interested in finding out whether the public policies and institutions factors influencing economic growth 
have changed over time. Second, the current study is superior to that by Dao [16] in that we specify a neoclassical growth model which incorporates public policies and institutions and subsequently formulate an empirical model to be estimated. This approach not only provides a more solid theoretical framework but also yields better empirical results that are not biased due to model misspecification. Based on data from the World Bank for the 2000-2015 period and a sample of thirty-nine ${ }^{i}$ developing economies we find that the growth rate of GDP is dependent on a country's economic management of its debt policy, its structural policies regarding the financial sector and the business regulatory environment, and its policies for social inclusion and equity dealing with gender equality, with building human resources, and with social protection and labor, along with the growth rates of inputs such as land, physical capital, general government consumption, and net exports. We observe that the coefficient estimates of two explanatory variables, namely, the structural policies regarding the financial sector and the policies for social inclusion and equity dealing with gender equality, do not have their expected sign, possibly to the collinearity between the structural policies regarding the financial sector and the debt policy variable, the business regulatory environment variable, the building human resources variable, and the social protection and labor variable and that between the gender equality variable and the business regulatory environment variable, the building human resources variable, and the social protection and labor variable. We also note that the business regulatory variable is not significant using the t-test, but its exclusion from the model results in a decrease in its explanatory power as measured by the adjusted coefficient of determination. We suspect that this is also due to the collinearity between this variable and three policies for social inclusion and equity variables. Statistical results of such empirical examination will assist governments in developing countries focus on appropriate policies dealing with the economic management of debt policy, those of a structural nature regarding the financial sector and the business regulatory environment, and those for social inclusion and equity such as improving gender equality, building human resources and providing social protection and labor in order to foster economic growth. Public sector management and institutions, on the other hand, do not seem to influence a developing country's rate of economic growth.

This paper is organized as follows. In the next section, a selected review of the economic literature on the effect of public policies and institutions on economic growth is discussed. This is followed by the formulation of a neoclassical growth model based on the aggregate production function. We then specify a statistical model to be estimated. Theoretical underpinnings for the inclusion of explanatory variables are presented in this section. Empirical results are reported in the subsequent section. A final section gives concluding remarks as well as policy recommendations.

\section{A Selected Review of the Literature}

Much of the research on the identification of the key determinants of economic growth in developing countries recently points to differences in underlying public policies and institutions as the main factor. Knack and Keefer [2] examine the impact of property rights on economic growth using indicators provided by country risk evaluators to potential foreign investors such as evaluations of contract enforceability and risk of expropriation. They find that property rights have a greater impact on investment and growth than has previously been found for proxies such as the Gastil indices of liberties, and frequencies of revolutions, coups and political assassinations. Rates of convergence to U.S.-level incomes increase notably when these property rights variables are included in growth regressions. These results are robust to the inclusion of measures of factor accumulation and of economic policy. Mauro [3] on the other hand analyzes a newly assembled data set consisting of subjective indices of corruption, the amount of bureaucracy, the efficiency of the judicial system, and various categories of political stability for a cross section of countries and finds that corruption lowers investment, thereby lowering economic growth. His results are robust to controlling for endogeneity by using an index of ethno linguistic fractionalization as an instrument.

Tanzi and Davoodi [4] demonstrate that high and rising corruption increases income inequality and poverty by reducing economic growth, the progressivity of the tax system, the level and effectiveness of social spending, and the formation of human capital, and by perpetuating an unequal distribution of asset ownership and unequal access to education. These findings hold for countries with different growth experiences, at different stages of development, and using various indices of corruption. An important implication of these results is that policies that reduce corruption will also lower income inequality and poverty.

Hall and Jones [5] document that the differences in capital accumulation, productivity, and therefore output per worker are driven by differences in institutions and government policies, which they call social infrastructure. They treat the latter as determined historically by location and other factors captured partly by language. In a cross-section of more than 150 countries, Kaufmann, Kraay, and Zoido-Lobaton [6] provide new empirical evidence of a strong causal relationship from better governance to better development outcomes. They base their analysis on a new database containing more than 300 governance indicators compiled from a variety of sources. Using an unobserved components methodology, they then construct six aggregate indicators corresponding to six basic governance concepts: voice and accountability, political instability and violence, government effectiveness, regulatory burden, rule of law, and graft. As measured by these indicators, governance matters for development outcomes.

Empirical studies have used a myriad of variables as 
proxies for institutions, which include measures of the risk of expropriation, the limits to the power of the executive branch and the power of the rule of law (see, for example, Hall and Jones [5] and Acemoglu, Johnson and Robinson [6]). Frankel and Romer [7], on the other hand, identify as a primary factor of economic development as measured by per capita income specific economic policies such as the extent to which a country is open to international trade, while Gallup, Sachs and Mellinger [8] attribute development to geographical determinants such as differences in climate and coastal access.

Using instrumental variable regressions, Rodrik, Subramanian and Trebbi [9] evaluate the main competing explanations, namely good institutions and good economic policies as well as geography and show that institutions measured as a variable defining the strength of the rule of law are dominant relative to both economic policy measured as the degree of openness to international trade and geography in terms of explaining cross-country variations in per capita income levels. Glaeser, La Porta, Lopez-de-Silanes, and Shleifer [10] however, revisit the issue of whether political institutions lead to economic growth or growth and human capital accumulation cause to better institutions. They argue that most indicators of institutional quality are conceptually unsuitable for being used in explaining growth and also find flaw in some of the instrumental variable techniques used in the literature. Their basic OLS results suggest that education levels are a more basic source of growth rather than institutions. Djankov, McLiesh, and Ramalho [11] use objective measures of business regulations in 135 countries find a positive relationship between better regulations as measured by the Doing Business indicator and economic growth.

More recently, Gillanders and Whelan [12] argue that the emphasis on the primacy of legal and political institutions may be misleading and argue that business-friendly economic policies as proxied by the World Bank's Doing Business indicators are the main factor contributing to cross-country differences in per capita income levels. They find that the Doing Business rank is dominant over a range of measures of legal and political institutional quality in terms of explaining variations in per capita income. They also find the rank to be statistically significant in explaining cross-country differences in economic growth while observing that the significant role of educational attainment as found by previous studies is not supported when the rank is included in their growth regressions.

Dao [13] empirically examines the role of political institutions and governance, of the judicial system, and of regulation in impacting economic performance of developing countries. Using data from the World Bank and the Global Competitiveness Report 2008-2009 for a sample of ninety-seven developing economies, he finds that government institutions do affect economic development in these countries, unlike the results of previous studies by $\mathrm{Mc}$ Arthur and Sachs [14] and Sachs [15]. He observes that the coefficient estimate of half of the independent variables used as proxies for the role of institutions does not have the anticipated sign due to the severe degree of multicollinearity among statistically significant explanatory variables. Regression results are more robust when interaction terms are included in the statistical model.

$\mathrm{He}$ is able to show that economic performance is linearly dependent on various indicators of governance and political institutions.

In a subsequent study, Dao [16] examines the impact of public policies and the business environment on economic growth in developing countries. Based on data from the World Bank for the 2000-2011 period and a sample of fifty-six low-income and lower middle-income economies he finds that the growth rate of per capita GDP is dependent on a country's economic management, its structural policies, its policies for social inclusion and equity, the number of procedures to build a warehouse, and the cost of starting a business as a percent of per capita income. He observes that the coefficient estimates of two explanatory variables, namely, the structural policies average and the number of procedures to build a warehouse, do not have their expected sign, possibly to the collinearity between the structural policies average variable and the economic management average variable as well as the policies for social inclusion and equity average variable.

The current study is superior to that by Dao [16] in that we specify a neoclassical growth model which incorporates public policies and institutions and subsequently formulate an empirical model to be estimated. This approach not only provides a more solid theoretical framework but also yields better empirical results that are not biased due to model misspecification. Empirical results are presented in a subsequent section. The final section gives concluding remarks as well as policy implications.

\section{The Theoretical Framework}

In deriving the GDP growth model, we shall make use of the rather traditional approach of the aggregate production function:

$$
\mathrm{Y}=\mathrm{f}(\mathrm{K}, \mathrm{L}, \mathrm{N}, \mathrm{G}, \mathrm{X}-\mathrm{M})
$$

Where $\mathrm{Y}$ is income, $\mathrm{K}$ is physical capital, $\mathrm{L}$ is land, $\mathrm{N}$ is labor, $\mathrm{G}$ is government used as an input, and $\mathrm{X}-\mathrm{M}$ is net exports.

Differentiating (1) above, one obtains:

$$
d Y=f_{K} d K+f_{L} d L+f_{N} d N+f_{G} d G+f_{X-M} d(X-M)
$$

Dividing through by $\mathrm{Y}$ to express the change as growth rate and after some manipulation, one gets:

$$
y=f_{M}(d K / Y)+\alpha_{L} l+\alpha_{N} n+\alpha_{G} g+\alpha_{X-M}(x-m)
$$

where lower case variables indicate growth rates, and $\alpha_{i}$ is the elasticity of output with respect to input i. To incorporate the effect of public policies and institutions on growth, one simply adds the public policies and institutions ratings to the model. 


\section{The Statistical Model}

To estimate the impact of public policies and institutions on economic growth we shall make use of the criteria set out by the World Bank Group's International Development Association (IDA). This organization helps the poorest countries reduce their poverty level by giving concessional loans and grants for those programs designed to foster economic growth and raise living standards. It assesses a country's performance using a set of 16 criteria that are grouped into four clusters: economic management, structural policies, policies for social inclusion and equity, and public sector management and institutions. Each criterion is rated on a scale ranging from 1 (low) to 6 (high). The economic management cluster includes the following criteria: macroeconomic management, fiscal policy, debt policy. The criteria which make up the structural policies cluster are: trade, financial sector, and business regulation environment. The policies for social inclusion and equity cluster include the following criteria: gender equality, equity of public resource use, building human resources, social protection and labor, and policies and institutions for environmental sustainability. The criteria which make up the public sector management and institutions cluster are: Property rights and rule-based governance, quality of budgetary and financial management, efficiency of revenue mobilization, quality of public administration, and transparency, accountability, and corruption in the public sector.

To estimate the impact of public policies and institutions on economic growth we specify the following statistical model:

$$
\begin{aligned}
& y=\beta_{0}+\beta_{1} \text { Landgrwth }+\beta_{2} \text { IYY2015 }+\beta_{3} l+\beta_{4} g 00-14+\beta_{5} n x 00-14+\beta_{6} \text { IDAIndx } \\
& \text { (+) } \quad(+) \quad(+) \quad(+) \quad(+) \quad(+) \\
& +\beta_{7} \text { MacroMgmt }+\beta_{8} \text { FiscPolicy }+\beta_{9} \text { DebtPolicy }+\beta_{10} \text { Trade }+\beta_{11} \text { FinSector } \\
& \text { (+) } \quad(+) \quad(+) \quad(+) \quad(+) \\
& +\beta_{12} \text { BusRegEnv }+\beta_{13} \text { Gender }+\beta_{14} \text { PubResUse }+\beta_{15} \text { HumRes }+\beta_{16} \text { SocProtct } \\
& \begin{array}{lllll}
(+) & (+) & (+) & (+) & (+)
\end{array} \\
& +\beta_{17} \text { EnvSustn }+\beta_{18} \text { PropR\&RulGvce }+\beta_{19} \text { Bud\&FinMgmt }+\beta_{20} \text { RevMobil } \\
& \text { (+) (+) (+) (+) } \\
& +\beta_{21} P u b A d m+\beta_{22} P u b S e c+\epsilon \\
& \text { (+) (+) }
\end{aligned}
$$

where $y=$ Average annual growth rate of GDP, 2000-15.

Landgrwth = Average annual growth rate of arable land per person (low) to 6 (high), 2000-14.

$I / Y 2015=$ Share of gross capital formation in the GDP, in 2015.

$l=$ Labor force growth rate, 2005-14.

g00-14= Annual growth rate of general government consumption, 2000-14.

$n x 00-14=$ Annual growth rate of net exports, in 2000-14.

IDAInd $x=$ IDA resource allocation index, $(1=$ low to $6=$ high $)$, in $2015^{\mathrm{ii}}$.

MacroMgmt $=$ CPIA macroeconomic management rating, $(1=$ low to $6=$ high $)$, in $2015^{\mathrm{iii}}$.

FiscPolicy $=$ CPIA fiscal policy rating, $(1=$ low to $6=$ high $)$, in $2015^{\text {iv }}$.

DebtPolicy $=$ CPIA debt policy rating, $(1=$ low to $6=$ high $)$, in $2015^{\mathrm{v}}$.

Trade $=$ CPIA trade rating, $(1=$ low to $6=$ high $)$, in $2015^{\mathrm{vi}}$.

FinSector $=$ CPIA financial sector rating, $(1=$ low to $6=$ high $)$, in $2015^{\text {vii }}$.

BusRegEnv = CPIA business regulatory environment rating, (1=low to 6=high), in 2015 .

Gender $=$ CPIA gender equality rating, $(1=$ low to $6=$ high $)$, in $2015^{\text {viii }}$.

PubResUse = CPIA equity of public resource use rating, ( $1=$ low to $6=$ high $)$, in $2015^{\text {ix }}$.

HumRes $=$ CPIA building human resources rating, $(1=$ low to $6=$ high $)$, in $2015^{\mathrm{x}}$.

SocProtct $=$ CPIA social protection rating, $(1=$ low to $6=$ high $)$, in $2015^{\mathrm{xi}}$.

EnvSustn = CPIA policy and institutions for environmental sustainability rating, (1=low to 6=high), in $2015^{\text {xii }}$.

PropR\&RulGvce $=$ CPIA property rights and rule-based governance rating, (1=low to $6=$ high), in $2015^{\text {xiii }}$.

Bud\&FinMgmt $=$ CPIA quality of budgetary and financial management rating, $(1=$ low to $6=$ high $)$, in $2015^{\text {xiv }}$.

RevMobil $=$ CPIA efficiency of revenue mobilization rating, (1=low to $6=$ high), in $2015^{\mathrm{xv}}$.

PubAdm = CPIA quality of public administration rating, $(1=$ low to $6=$ high $)$, in $2015^{\mathrm{xvi}}$.

PubSec $=$ CPIA transparency, accountability, and corruption in the public sector rating, $(1=$ low to $6=$ high $)$, in $2015^{\text {xvii }}$

$\varepsilon=$ random error term, with mean 0 and uniform variance. 
We use the 2000-2015 GDP growth rate at market prices based on constant local currency for $y$. We expect the coefficient estimates for all five input growth variables as well as those for public policies and institutions ratings to have a positive sign. Data for all variables are from the 2016 World Bank Indicators [17].

\section{Empirical Results}

Table 1 gives least-squares estimates of regression coefficients in equation (4) for a sample of thirty-nine low-income and lower middle-income countries ${ }^{\text {xviii }}$. We observe that eight of the explanatory variables are statistically significant at the 10 percent or lower level and only five coefficient estimates do have their anticipated sign. The goodness of fit of the model is quite good as indicated by the value of 0.446 of the adjusted coefficient of determination.

Table 1. Dependent Variable: GDP Growth Rate

\begin{tabular}{|c|c|c|}
\hline & Coefficient Estimates & t-Statistics \\
\hline Intercept & -3.275 & -1.019 \\
\hline Landgrwth & 0.238 & $1.523^{*}$ \\
\hline I/Y2015 & 0.069 & $1.983^{* *}$ \\
\hline 1 & 0.397 & 1.160 \\
\hline g00-14 & 0.081 & $1.567^{*}$ \\
\hline nx00-14 & 0.157 & $1.792^{* *}$ \\
\hline IDAIndx & -2.572 & -0.734 \\
\hline DebtPolicy & 1.170 & $1.696^{*}$ \\
\hline FinSector & -1.706 & $-2.055^{* *}$ \\
\hline BusRegEnv & 0.943 & 1.047 \\
\hline Gender & -0.907 & -1.019 \\
\hline HumRes & 2.128 & $1.793^{* *}$ \\
\hline Soc Protct & 1.979 & $2.125^{* *}$ \\
\hline EnvSustn & -0.744 & -0.767 \\
\hline Bud\&FinMgmt & 0.557 & 0.477 \\
\hline PubAdm & 0.810 & 0.624 \\
\hline PubSec & -0.290 & -0.377 \\
\hline
\end{tabular}

Adjusted $\mathrm{R}^{2}=0.446$

*Significant at the 10 percent level.

**Significant at the 5 percent level.

A backward elimination stepwise method was applied to arrive at a revised model, the regression results of which are reported in Table 2. We note that the goodness of fit of the model to the data is better as indicated by the higher value of 0.498 of the adjusted coefficient of determination. We observe that all but one explanatory variables are statistically significant at the 10 percent or lower level while two coefficient estimates do not have their expected positive sign. A possible explanation for this result may be due to the extent of multicollinearity.

Table 2. Dependent Variable: GDP Growth Rate (Revised Model)

\begin{tabular}{|c|c|c|}
\hline & Coefficient Estimates & t-Statistics \\
\hline Intercept & -3.059 & -1.348 \\
\hline Landgrwth & 0.204 & $1.474^{*}$ \\
\hline I/Y2015 & 0.055 & $2.027^{* *}$ \\
\hline g00-14 & 0.071 & $1.694^{*}$ \\
\hline nx00-14 & 0.130 & $1.618^{*}$ \\
\hline DebtPolicy & 0.737 & $1.819^{* *}$ \\
\hline FinSector & -2.062 & $-2.966^{* * *}$ \\
\hline BusRegEnv & 0.884 & 1.214 \\
\hline Gender & -1.585 & $-2.354^{* *}$ \\
\hline HumRes & 2.152 & $2.139^{* *}$ \\
\hline Soc Protct & 1.550 & $2.205^{* *}$ \\
\hline
\end{tabular}

Adjusted $\mathrm{R}^{2}=0.498$

*Significant at the 10 percent level.

**Significant at the 5 percent level.

***Significant at the 1 percent level

Ceteris paribus, as per capita arable land growth increases by one percentage point, we would expect a country's GDP growth rate to increase by 0.20 percentage point, while a one percentage point increase in the share of gross capital formation in the GDP results in an expected increase of 0.06 percentage point in the GDP growth rate. On the other hand, a one-percentage point increase in growth of general government consumption leads to an expected increase of 0.07 percentage point in the GDP growth rate, all else equal.

As net exports growth increases by one percentage point, one can expect GDP growth to increase by 0.13 , holding everything else constant. A one-unit increase in debt policy rating is expected to lead to a 0.74 percentage point increase in GDP growth, ceteris paribus, while a one-unit increase in building human resources rating is expected to result in an increase of 2.15 percentage points in GDP growth. As the social protection and labor rating increases by one unit, one can expect GDP growth rate to increase by 1.55 percentage point, all else equal.

We also note that while the business regulatory environment rating is not statistically significant using t-test, its exclusion from the model decreases its explanatory power, as measured by the adjusted coefficient of determination. A one-unit increase in this rating is expected to lead to an increase of 0.88 percentage point in GDP growth, ceteris paribus. We suspect that due to the extent of the multicollinearity problem among explanatory variables, this variable is not statistically significant based on t-tests while the coefficient estimates on the financial sector rating and the gender equality rating do not have their anticipated positive sign. We report this extent in table 3 in the form of a sample correlation coefficient matrix. 
Table 3. Sample Correlation Coefficient Matrix

\begin{tabular}{|c|c|c|c|c|c|c|c|c|c|c|}
\hline & Landgrwth & $\mathrm{I} / \mathrm{Y} 2015$ & g00-14 & $\mathrm{nx} 00-14$ & DebtPolicy & FinSector & BusRegEnv & Gender & HumRes & Soc Protct \\
\hline Landgrwth & 1 & & & & & & & & & \\
\hline \multirow[t]{2}{*}{ I/Y2015 } & -0.156 & 1 & & & & & & & & \\
\hline & -0.960 & & & & & & & & & \\
\hline \multirow[t]{2}{*}{$\mathrm{g} 00-14$} & -0.008 & -0.217 & 1 & & & & & & & \\
\hline & -0.051 & -1.355 & & & & & & & & \\
\hline \multirow[t]{2}{*}{$\mathrm{nx} 00-14$} & 0.243 & -0.158 & -0.214 & 1 & & & & & & \\
\hline & 1.523 & -0.976 & -1.332 & & & & & & & \\
\hline \multirow[t]{2}{*}{ DebtPolicy } & 0.026 & 0.125 & -0.305 & 0.081 & 1 & & & & & \\
\hline & 0.155 & 0.766 & -1.948 & 0.492 & & & & & & \\
\hline \multirow[t]{2}{*}{ FinSector } & 0.031 & 0.054 & 0.131 & -0.137 & 0.386 & 1 & & & & \\
\hline & 0.190 & 0.331 & 0.803 & -0.840 & 2.544 & & & & & \\
\hline \multirow[t]{2}{*}{ BusRegEnv } & -0.008 & 0.248 & -0.202 & 0.206 & 0.371 & 0.323 & 1 & & & \\
\hline & -0.049 & 1.560 & -1.257 & 1.279 & 2.431 & 2.074 & & & & \\
\hline \multirow[t]{2}{*}{ Gender } & 0.023 & 0.327 & 0.002 & -0.210 & 0.240 & -0.009 & 0.337 & 1 & & \\
\hline & 0.140 & 2.108 & 0.015 & -1.304 & 1.503 & -0.052 & 2.179 & & & \\
\hline \multirow[t]{2}{*}{ HumRes } & -0.132 & 0.448 & 0.044 & -0.188 & 0.267 & 0.342 & 0.573 & 0.691 & 1 & \\
\hline & -0.808 & 3.049 & 0.270 & -1.165 & 1.684 & 2.216 & 4.248 & 5.821 & & \\
\hline \multirow[t]{2}{*}{ Soc Protct } & 0.113 & 0.026 & 0.002 & 0.100 & 0.429 & 0.469 & 0.569 & 0.303 & 0.378 & 1 \\
\hline & 0.694 & 0.159 & 0.009 & 0.611 & 2.887 & 3.231 & 4.209 & 1.937 & 2.484 & \\
\hline
\end{tabular}

Note: Bold t-statistics imply statistical significance at the 10 percent or lower level.

We observe that the business regulatory environment rating is linearly related to the gender equality rating, the building human resources rating, and the social protection and labor rating as well as to the financial sector rating, while the financial sector rating itself is correlated with the building human resources rating and with the debt policy rating as well as with the social protection and labor rating. On the other hand, the gender equality rating is linearly related to both the building human resources rating and the social protection and labor rating.

\section{Conclusions}

In this paper, we develop a growth model based on the traditional approach of the aggregate production function while incorporating the effects of both public policies and institutions and specify an econometric model to examine the effect of these public policies and institutions ratings on economic growth using data from a sample of thirty-nine low-income and lower-middle income economies. From the statistical results, we are able to draw the following conclusions and policy implications:

1. Within the set of thirty-nine developing economies used in this study, from the economic management cluster, debt policy rating has a significant and positive impact on economic growth. Governments in these countries need to have a debt management strategy that is conducive to minimizing budgetary risks and ensuring long-term debt sustainability in order to facilitate economic growth.

2. Within the structural policies cluster, financial sector and business regulatory environment ratings are important in influencing economic growth. Governments in low-income and lower-middle income countries need to provide a strong financial sector as well as a favorable business regulatory environment to encourage further growth. 
3. Within the policies for social inclusion and equity cluster, gender equality, building human resources, and social protection and labor ratings are critical for economic growth. Governments in low-income and lower-middle income economies need to install institutions and programs to enforce laws and policies that promote equal access for men and women in education, health, the economy, and protection under the law while implementing the national policies and public and private sector service delivery that affect the access to and quality of health and education services, including prevention and treatment of HIV/AIDS, tuberculosis, and malaria and those policies in social protection and labor market regulations that reduce the risk of becoming poor, assist those who are poor to better manage further risks, and ensure a minimal level of welfare to all people.

4. policies in social protection and labor market regulations that reduce the risk of becoming poor, assist those who are poor to better manage further risks, and ensure a minimal level of welfare to all people in order to enhance economic growth.

5. Public sector management and institutions do not seem to influence economic growth in low-income and lower-middle income countries.

\section{Acknowledgements}

I would like to thank Thi Minh Chi Le for her support during the completion of this paper.

\section{REFERENCES}

[1] World Bank (2013), World Development Report 2013: Jobs, Oxford University Press: New York, NY.

[2] Knack, S. and Keefer, P. (1995), "Institutions and Economic Performance: Cross-country Test Using Alternative Institutional Methods," Economics and Politics, Vol. 7, No. 3, pp. 207-27.

[3] Mauro, P. (1995), "Corruption and Economic Growth," Quarterly Journal of Economics, Vol. 110, No. 3, pp. 682-712.

[4] Tanzi, V. and Davoodi, H. (1998), "Does Corruption Affect Income Inequality and Poverty?" Washington, D.C.: International Monetary Fund Working Paper No. 98/76.

i The sample consists of the following countries: Bangladesh, Benin Bhutan, Bolivia, Burkina Faso, Burundi, Cambodia, Cameroon, Central African Republic, Democratic Republic of Congo, Republic of Congo, The Gambia, Honduras, Kenya, Kyrgyz Republic, Lao PDR, Lesotho, Liberia, Madagascar, Malawi, Mali, Mauritania, Moldova, Mongolia, Mozambique,
[5] Hall, R.E. and Jones, C.I. (1999), "Why Do Some Countries Produce So Much More Output per Worker than Others?" Quarterly Journal of Economics 114 (1), 83-116.

[6] Kaufmann, D., Kraay, A., and Zoido-Lobatón (1999), "Governance Matters," Washington, D.C.: World Bank Policy Research Working Paper No. 2196.

[7] Acemoglu, D., Johnson, S. and Robinson, J.A. (2001), "The Colonial Origins of Comparative Development: An Empirical Investigation," American Economic Review, 91 (5), $1369-1401$.

[8] Frankel, J.A, and Romer, D. (1999), "Does Trade Cause Growth?" American Economic Review 89 (3), 379-399.

[9] Gallup, J.L., Sachs, J.D., and Mellinger, A. (1999), "Geography and Economic Development," CID Working Papers 1, Center for International Development at Harvard University, March.

[10] Rodrik, D., Subramanian, A., and Trebbi, F. (2004), "Institutions Rule: The Primacy of Institutions over Geography and Integration in Economic Development," Journal of Economic Growth 9 (2), 131-165.

[11] Glaeser, E.L., La Porta, R., Lopez-de-Silanes, F., and Shleifer, A. (2004), "Do Institutions Cause Growth?" NBER Working Paper 10568.

[12] Djankov, S., McLiesh, C., and Ramalho, R. M. (2006), "Regulation and Growth," Economics Letters 92 (3), 395-401.

[13] Gillanders, R. and Whelan, K. (2010), "Open for Business? Institutions, Business Environment and Economic Development," University College Dublin School of Economics Working Papers No. 20104, December.

[14] Dao, M.Q. (2011), "Institutions and Development in Developing Countries: An Empirical Assessment," Perspectives on Global Development and Technology, 10 (2), 327-338.

[15] McArthur, J.W. and Sachs, J.D. (2001). "Institutions and Geography: Comment on Acemoglu, Johnson and Robinson (2000)," Cambridge, MA: National Bureau of Economic Research Working Paper No. 8114.

[16] Sachs, J.D. (2003) "Institutions Don’t Rule: Direct Effects of Geography on Per Capita Income," Cambridge, MA: National Bureau of Economic Research Working Paper No. 9490.

[17] Dao, M.Q. (2013), "Public Policies, Business Environment, and Economic Growth in Developing Countries," International Journal of Research in Commerce, Economics \&Management, Vol. No. 3, Issue No. 6 (June 2013): 1-4.

[18] World Bank (2016), World Development Indicators, Oxford University Press: New York, NY.

Nepal, Nicaragua, Nigeria, Pakistan, Rwanda, Senegal, Sierra Leone, Sudan, Tajikistan, Tanzania, Togo, Uganda, Vietnam, and Zimbabwe.

ii IDA Resource Allocation Index is obtained by calculating the average score for each cluster and then by averaging those scores. For each of the 16 criteria, countries are rated on a scale of 1 (low) to 6 (high).

iii Macroeconomic management assesses the monetary, exchange rate, and aggregate demand policy framework. 
iv Fiscal policy assesses the short- and medium-term sustainability of fiscal policy (taking into account monetary and exchange rate policy and the sustainability of the public debt) and its impact on growth.

$\mathrm{v}$ Debt policy assesses whether the debt management strategy is conducive to minimizing budgetary risks and ensuring long-term debt sustainability.

vi Trade assesses how the policy framework fosters trade in goods.

vii Financial sector assesses the structure of the financial sector and the policies and regulations that affect it.

viii Gender equality assesses the extent to which the country has installed institutions and programs to enforce laws and policies that promote equal access for men and women in education, health, the economy, and protection under law.

ix Equity of public resource use assesses the extent to which the pattern of public expenditures and revenue collection affects the poor and is consistent with national poverty reduction priorities.

$\mathrm{x}$ Building human resources assesses the national policies and public and private sector service delivery that affect the access to and quality of health and education services, including prevention and treatment of HIV/AIDS, tuberculosis, and malaria.

xi Social protection and labor assess government policies in social protection and labor market regulations that reduce the risk of becoming poor, assist those who are poor to better manage further risks, and ensure a minimal level of welfare to all people.

xii Policy and institutions for environmental sustainability assess the extent to which environmental policies foster the protection and sustainable use of natural resources and the management of pollution.

xiii Property rights and rule-based governance assess the extent to which private economic activity is facilitated by an effective legal system and rule-based governance structure in which property and contract rights are reliably respected and enforced. xiv Quality of budgetary and financial management assesses the extent to which there is a comprehensive and credible budget linked to policy priorities, effective financial management systems, and timely and accurate accounting and fiscal reporting, including timely and audited public accounts.

$\mathrm{xV}$ Efficiency of revenue mobilization assesses the overall pattern of revenue mobilization - not only the de facto tax structure, but also revenue from all sources as actually collected.

xvi Quality of public administration assesses the extent to which civilian central government staff is structured to design and implement government policy and deliver services effectively.

xvii Transparency, accountability, and corruption in the public sector assess the extent to which the executive can be held accountable for its use of funds and for the results of its actions by the electorate and by the legislature and judiciary, and the extent to which public employees within the executive are required to account for administrative decisions, use of resources, and results obtained. The three main dimensions assessed here are the accountability of the executive to oversight institutions and of public employees for their performance, access of civil society to information on public affairs, and state capture by narrow vested interests.

xviii Since macroeconomic management, fiscal policy, trade, equity of public resource use, property rights and rule-based governance, and the International Development Association (IDA) resource allocation index were found to be non-significant, they are excluded from the model. Results with their inclusion are available from the author upon request. 